\title{
Ventricular mass and diastolic function in patients infected by the human immunodeficiency virus
}

\author{
T Martínez-García, J M Sobrino, E Pujol, J Galvez, E Benítez, J A Girón-González
}

\begin{abstract}
Objective-Echocardiographic and Doppler analysis of myocardial mass and diastolic function in patients infected with HIV.

Design-Case-control study.

Setting-Tertiary referral centre, Huelva, Spain.

Patients-61 asymptomatic patients with HIV infection and 32 healthy controls.

Main outcome measures-Time motion, cross sectional, and Doppler echocardiographic studies were performed, and left ventricular mass and diastolic function variables determined (peak velocity of early and late mitral outflow and isovolumic relaxation time).

Results-Left ventricular mass index (LVMI) was decreased in patients compared with healthy controls (mean (SD): 76.7 (23.6) v 118.8 (23.5) g/m², p < 0.001). Linear regression analysis showed a correlation between LVMI and brachial fat and muscle areas. The ratio of peak velocities of early and late mitral outflow was decreased in HIV infected patients compared with controls $(1.19(0.44) v 1.58(0.38), \mathrm{p}<0.001)$. This ratio was exclusively related to haemodynamic variables (heart rate, systolic and diastolic blood pressures). HIV infected patients had a prolonged isovolumic relaxation time $(103.0(10.5) v 72.9(12.9) \mathrm{ms}, \mathrm{p}<0.001)$. Isovolumic relaxation time was correlated only with brachial muscle area on multivariate analysis.

Conclusions-HIV infected patients had a reduced left ventricular mass index and diastolic functional abnormalities. These cardiac abnormalities are predominantly related to nutritional status.
\end{abstract}

(Heart 2000;84:620-624)

Keywords: HIV infection; cardiac function; nutrition

Cardiac manifestations of HIV infection include pericardial effusions, disturbances of rhythm, malignant infiltration, marasmic endocarditis, and heart muscle disease. ${ }^{1-3}$ These cardiac abnormalities can be detected in necropsy series in the majority $(40-60 \%)$ of HIV infected patients, although clinical symptoms are infrequent. ${ }^{1-9}$ Echocardiography and Doppler ultrasound studies are useful instruments for detecting cardiac alterations in asymptomatic patients. In general, echocardiographic abnormalities are more often detected in patients with reduced numbers of CD4+ lymphocytes $/ \mathrm{mm}^{3}$, in those with respiratory or cardiac symptomatology, or in those in whom parenteral drug misuse was the HIV risk factor. $^{210}$ The co-occurrence of several factors in the same patient and the lack of multivariate analysis make interpretation of these published data difficult.

Both left ventricular mass and systolic function have been studied. ${ }^{71}$ Cardiac pathological abnormalities have been attributed to HIV infection of myocytes or dendritic cells, ${ }^{4}$ opportunistic infections or neoplasms, ${ }^{5}$ effects of the treatment, ${ }^{6}$ or alterations in nutritional status. ${ }^{7}$ A correlation with serum virus load has not been made, although the presence of HIV in cardiac tissue has been demonstrated. ${ }^{4}$

It is theoretically probable that diastolic dysfunction precedes systolic abnormalities in HIV infected patients. However, studies examining diastolic function in these individuals are sparse. ${ }^{11}$ For this reason, we examined $61 \mathrm{HIV}$ infected patients in a prospective echocardio- graphic study, the principal aims of which were to analyse myocardial mass and diastolic function and to determine the independent influence on these variables of virus load, immune status, anthropometric measurements, presence of opportunistic infections, and antiretroviral treatment.

\section{Methods}

PATIENTS

From March to June 1996, 61 patients with HIV infection (mean (SD) age, 32.7 (5.0) years) were studied prospectively. To avoid differences attributable to sex, only men were studied. These were randomly selected from outpatients attending the AIDS clinic of the Hospital Juan Ramón Jiménez, Huelva, southern Spain. This centre serves a population of 240173 inhabitants. The prevalence of AIDS in this population approaches 877 cases/ million.

Infection by HIV had been diagnosed by enzyme immunoassay and confirmed by western blot analysis. Patients were classified according to Centers for Diseases Control (CDC) criteria. $^{12}$

Patients with previous or current endocarditis, cardiomyopathy (ischaemic, hypertrophic, congenital, or rheumatic), clinical or radiographic suspicion of cardiac disease, liver insufficiency (B or C Child class), kidney failure (plasma creatinine $\geqslant 133 \mu \mathrm{mol} / \mathrm{l}$ ), ethanol abuse ( $>50 \mathrm{~g} /$ day ethanol), or active parenteral drug use were excluded from the protocol. 
Healthy controls $(n=32)$ were selected from age matched hospital workers (mean (SD) age, 30.9 (7.9) years) without heart disease or serological evidence of HIV infection. There was no risk factor for HIV infection in these individuals.

Patients and controls underwent uniform clinical evaluation including history and physical examination. The following data were recorded for each patient: age, sex, HIV transmission risk factor, time from diagnosis of HIV infection, clinical data compatible with opportunistic diseases, antiretroviral treatment, and presence of symptoms attributable to cardiac disease. We found no symptoms of heart disease in either the HIV infected patients or the healthy controls.

Anthropometric measurements included height $(\mathrm{cm})$, weight $(\mathrm{kg})$, body mass index (BMI, $\mathrm{kg} / \mathrm{m}^{2}$ ), triceps skinfold thickness ( $\mathrm{mm}$ ), mid-arm fat area $\left(\mathrm{cm}^{2}\right)$, and mid-arm muscle area $\left(\mathrm{cm}^{2}\right)$. These measurements were determined as described previously ${ }^{13}$ :

$$
\begin{aligned}
& \text { Midarm fat area }= \\
& \frac{[\text { mid-arm circumference } \times \text { triceps skinfold }]}{2} \\
& -\pi \times \frac{(\text { triceps skinfold })^{2}}{4}
\end{aligned}
$$

Midarm muscle area $=$

$\frac{[\text { mid-arm circumference }-\pi(\text { triceps skinfold })]^{2}}{4 \pi}$

Anthropometric measures of our control population were comparable to those obtained in our country from a healthy population. ${ }^{14}$ For comparison with control data, patients were classified as obese (BMI $\geqslant 90$ th centile of healthy controls, $31.7 \mathrm{~kg} / \mathrm{m}^{2}$ ), normal (BMI $>10$ th centile and $<90$ th centile, $21.7 \mathrm{~kg} / \mathrm{m}^{2}$ to $31.7 \mathrm{~kg} / \mathrm{m}^{2}$ ), or malnourished (BMI $\leqslant 10$ th centile, $21.7 \mathrm{~kg} / \mathrm{m}^{2}$ ).

For specific analyses, patients were classified as follows:

- Presence (CDC stage C) or absence (CDC stages $\mathrm{A}$ and $\mathrm{B}$ ) of previous opportunistic infections.

- A CD4+ cell count higher or lower than 200 $\times 10^{6}$ cells $/ 1$.

- A serum virus load higher or lower than 10000 copies $/ \mathrm{ml}$.

These cut off points were chosen to reflect clinically relevant clinical, immunological, and virological features.

The study protocol was approved by the institutional ethics committee and every patient and control gave his informed consent.

\section{LABORATORY PROCEDURES}

CD4+ cell counts were determined in HIV patients within one week of the echocardiographic study (Facscan flow cytometer, Becton Dickinson, San José, California, USA). Stored serum from blood taken at the time of ultrasound examination, available from 40 patients, was analysed for HIV virus load (Amplicor Roche, New Jersey, USA).
ECHOCARDIOGRAPHY

Time motion, cross sectional, and Doppler echocardiogram examinations were performed by a single experienced operator (JMS) using a ultrasonoscope (Acuson $128 \mathrm{XP} / 5 \mathrm{c}$, Mountain View, California USA) with 3.0 and $3.5 \mathrm{MHz}$ transducers. Measurements were made in accordance with recommendations of the American Society of Echocardiography. Three individual sets of measurements were obtained from each cross sectional echocardiogram, and the results were averaged. The discrepancy between measurements was less than $10 \%$ in every case.

Blood pressure was determined by sphygmomanometer at the end of the echocardiographic study, with the individual seated.

Time motion and pulsed Doppler recordings were performed on a strip chart thermal recorder at a paper speed of 50 or $100 \mathrm{~mm} / \mathrm{s}$. Timing of the cardiac cycle was documented by simultaneous ECG recording. Standard parasternal long and short axis and apical views (four chambers and four chambers with aorta) were obtained. We used M mode echocardiography to measure left ventricular end diastolic dimensions, the interventricular septum, and left ventricular posterior wall thickness in diastole. Posterior wall endocardial and epicardial recordings and left ventricular septal recordings were manually traced on a digitising tablet connected to a microcomputer (HewlettPackard 1000 (Andover, Massachusetts, USA), self devised software, data point recording at $10 \mathrm{~ms}$ intervals). Based on these data, left ventricular mass (Devereux's formula) and left ventricular mass index (LVMI) were calculated. ${ }^{15}$ In previous studies it has been estimated that the mean left ventricular mass by this method in a normal man is $177 \mathrm{~g}$, and the LVMI is $92 \mathrm{~g} / \mathrm{m}^{2} .^{16}$

We looked for valvar thickening and pericardial effusions in each patient. Slight mitral and tricuspid valve thickening without significant regurgitation was detected in five patients. Only one control had mild mitral valve prolapse.

Diastolic function indices were analysed by pulsed Doppler recordings, obtained on expiration, with the sample volume located between the tips of the mitral leaflets. We measured peak velocity of early (E wave) and late (A wave) mitral outflow $(\mathrm{m} / \mathrm{s}$ ) and the E/A ratio. The isovolumic relaxation time (seconds $\times 10^{-3}$ ), defined as the time interval between aortic valve closure and mitral opening, was measured from beat to beat recordings of left ventricular filling and ejection flows by pulsed Doppler. All values were averaged over three consecutive cardiac cycles.

STATISTICAL ANALYSIS

Results of quantitative variables are expressed as the arithmetical mean (SD), and those of categorical variables as absolute numbers followed by the percentage. Quantitative variables from the groups were compared using the Mann-Whitney U test. Categorical variables were compared using the $\chi^{2}$ or Fisher's exact 
Table 1 Characteristics of patients infected by HIV and healthy controls

\begin{tabular}{llll}
\hline Variable & $\begin{array}{l}\text { Healthy controls } \\
(n=32)\end{array}$ & $\begin{array}{l}\text { HIV infected } \\
\text { patients }(n=61)\end{array}$ & p Value \\
\hline Age (years) & $30.9(7.9)$ & $32.7(5.0)$ & \\
Previous drug parenteral users (n, \%) & $0(0)$ & $45(73.7)$ & \\
Time of evolution of HIV infection (months) & & $62.7(43.2)$ & \\
CD4+ cells (cells $\left.\times 10^{6} / 1\right)$ & & $289.4(351.8)$ & \\
Virus load (copies $\left.\times 10^{3} / \mathrm{mm}^{3}\right)$ & & $108.2(258.5)$ & \\
Stage of HIV infection $(\mathrm{n}, \%)$ & & $21(34.4)$ & \\
$\mathrm{A}$ & & $14(23.0)$ & \\
$\mathrm{B}^{\star}$ & & $26(42.6)$ & \\
$\mathrm{C}^{\star}$ & & $36(59.0)$ & $<0.01$ \\
Antiretroviral treatment $(\mathrm{n}, \%) \dagger$ & $76.2(13.5)$ & $63.3(9.5)$ & $<0.001$ \\
Weight $(\mathrm{kg})$ & $26.0(4.4)$ & $22.2(3.0)$ & $<0.001$ \\
Body mass index $\left(\mathrm{kg} / \mathrm{m}^{2}\right)$ & $16.5(7.7)$ & $8.2(3.6)$ & $<0.05$ \\
Triceps skinfold thickness $(\mathrm{cm})$ & $24.2(13.0)$ & $10.8(5.3)$ & \\
Mid-arm fat area $\left(\mathrm{cm}^{2}\right)$ & $44.1(8.5)$ & $38.9(9.2)$ & \\
Mid-arm muscle area $\left(\mathrm{cm}^{2}\right)$ & & & \\
\hline
\end{tabular}

Values are mean (SD) unless stated otherwise.

*Previous opportunistic diseases: pulmonary tuberculosis (8), disseminated tuberculosis (5), oesophageal candidiasis (5), cryptococcal meningitis (2), Kaposi sarcoma, Pneumocystis carinii pneumonia, cytomegalovirus retinitis, recurrent bacterial pneumonia, cerebral toxoplasmosis, and non-Hodgkin lymphoma (1 each).

tAntiretroviral treatment: AZT, 10 patients (16.4\%); ddI, 3 patients (4.9\%); AZT + ddI, 12 patients $(19.7 \%)$; AZT + ddC, 11 patients $(18.0 \%)$.

Table 2 Left ventricular mass and diastolic variables in healthy controls and patients infected by HIV

\begin{tabular}{|c|c|c|c|c|}
\hline \multirow[b]{2}{*}{ Variable } & \multirow[b]{2}{*}{$\begin{array}{l}\text { Healthy controls } \\
(n=32)\end{array}$} & \multicolumn{3}{|c|}{ HIV infected patients } \\
\hline & & $\begin{array}{l}\text { Overall } \\
(n=61)\end{array}$ & $\begin{array}{l}\text { Well nourished } \\
(n=35)\end{array}$ & $\begin{array}{l}\text { Malnourished } \\
(n=26)\end{array}$ \\
\hline Left ventricular mass $(\mathrm{g})$ & $222.5(44.8)$ & $132.4(44.3)^{\mathrm{c}}$ & $147.5(49.0)^{\mathrm{c}}$ & $112.1(26.5)^{\mathrm{c}, \mathrm{e}}$ \\
\hline $\begin{array}{l}\text { Left ventricular mass } \\
\text { index }\left(\mathrm{g} / \mathrm{m}^{2}\right)\end{array}$ & $118.8(23.5)$ & $76.7(23.6)^{c}$ & $83.3(26.7)^{c}$ & $67.8(14.8)^{\mathrm{c}, \mathrm{d}}$ \\
\hline $\begin{array}{l}\text { Left ventricular diastolic } \\
\text { diameter }(\mathrm{mm})\end{array}$ & $45.7(4.4)$ & $40.1(6.6)^{c}$ & $40.2(7.9)^{\mathrm{c}}$ & $40.0(4.6)^{c}$ \\
\hline $\begin{array}{l}\text { Maximum velocity of } \\
\text { the early ventricular } \\
\text { filling }\left(\mathrm{m} \cdot \mathrm{s}^{-1}\right)\end{array}$ & $0.79(0.15)$ & $0.68(0.21)^{\mathrm{b}}$ & $0.70(0.13)^{\mathrm{a}}$ & $0.65(0.28)^{\mathrm{a}}$ \\
\hline $\begin{array}{l}\text { Maximum velocity of } \\
\text { the late ventricular } \\
\text { filling }\left(\mathrm{m} \cdot \mathrm{s}^{-1}\right)\end{array}$ & $0.51(0.10)$ & $0.56(0.17)^{\mathrm{a}}$ & $0.61(0.11)^{\mathrm{c}}$ & $0.50(0.22)^{\mathrm{d}}$ \\
\hline $\mathrm{E} / \mathrm{A}$ ratio ${ }^{\star}$ & $1.58(0.38)$ & $1.19(0.44)^{\mathrm{c}}$ & $1.17(0.26)^{\mathrm{c}}$ & $1.22(0.61)^{\mathrm{a}}$ \\
\hline $\begin{array}{l}\text { Isovolumic relaxation } \\
\text { time }\left(\mathrm{s} \times 10^{-3}\right) \\
\text { Heart rate }(\text { beats } / \mathrm{min})\end{array}$ & $\begin{array}{l}72.9(12.9) \\
72.1(9.9)\end{array}$ & $\begin{array}{l}103.0(10.5)^{\mathrm{c}} \\
79.3(13.4)^{\mathrm{a}}\end{array}$ & $\begin{array}{l}105.7(8.0)^{\mathrm{c}} \\
76.7(9.6)\end{array}$ & $\begin{array}{l}99.5(12.6)^{\mathrm{c}} \\
82.7(16.8)^{\mathrm{a}}\end{array}$ \\
\hline $\begin{array}{l}\text { Systolic blood pressure } \\
(\mathrm{mm} \mathrm{Hg})\end{array}$ & $122.0(11.8)$ & $115.2(10.4)^{\mathrm{a}}$ & $118.4(9.5)$ & $111.0(10.2)^{\mathrm{c}, \mathrm{e}}$ \\
\hline $\begin{array}{l}\text { Diastolic blood pressure } \\
(\mathrm{mm} \mathrm{Hg})\end{array}$ & $75.8(8.1)$ & $69.3(9.3)^{\mathrm{b}}$ & $71.3(10.2)$ & $66.5(7.0)^{c}$ \\
\hline
\end{tabular}

Values are mean (SD).

${ }^{\star} \mathrm{E} / \mathrm{A}$ ratio: relation between peak velocity of early $(\mathrm{E})$ and late $(\mathrm{A})$ ventricular filling.

${ }^{a} \mathrm{p}<0.05 v$ healthy controls; ${ }^{\mathrm{b}} \mathrm{p}<0.01 v$ healthy controls; ${ }^{\mathrm{c}} \mathrm{p}<0.001 v$ healthy controls; ${ }^{\mathrm{d}} \mathrm{p}<0.05 v$ well nourished HIV infected patients; ${ }^{\mathrm{e}} \mathrm{p}<0.01 v$ well nourished HIV infected patients.

Table 3 Left ventricular mass and diastolic indices in patients infected by HIV, classified by CD4+ cells count, CDC stage, and virus load

\begin{tabular}{|c|c|c|c|}
\hline Variable & $\begin{array}{l}\text { Left ventricular } \\
\text { mass index } \\
\left(\mathrm{g} / \mathrm{m}^{2}\right)\end{array}$ & E/A ratio* & $\begin{array}{l}\text { Isovolumic } \\
\text { relaxation time } \\
\left(s \times 10^{-3}\right)\end{array}$ \\
\hline \multicolumn{4}{|l|}{ CD $4+\mathrm{T}$ cell $\times 10^{6} / 1$} \\
\hline$<200(\mathrm{n}=31)$ & $76.6(24.1)$ & $1.05(0.43)$ & $101.9(10.2)$ \\
\hline$>200(n=30)$ & $76.8(23.5)$ & $\begin{array}{l}1.34(0.40) \\
(p<0.05)\end{array}$ & $104.2(11.0)$ \\
\hline \multicolumn{4}{|l|}{ CDC class } \\
\hline$A-B(n=35)$ & $79.7(26.7)$ & $1.34(0.37)$ & $104.1(10.9)$ \\
\hline$C(n=26)$ & $72.6(18.0)$ & $\begin{array}{l}1.12(0.27) \\
(p<0.05)\end{array}$ & $100.4(9.5)$ \\
\hline \multicolumn{4}{|l|}{ Serum virus load } \\
\hline$<10000$ copies $/ \mathrm{ml}(\mathrm{n}=15)$ & $88.9(20.7)$ & $1.16(0.26)$ & $104.8(6.1)$ \\
\hline$>10000$ copies $/ \mathrm{ml}(\mathrm{n}=25)$ & $\begin{array}{l}74.1(22.0) \\
(p<0.01)\end{array}$ & $1.32(0.35)$ & $102.2(11.9)$ \\
\hline \multicolumn{4}{|l|}{ Antiretroviral treatment } \\
\hline Yes $(n=36)$ & $80.2(25.0)$ & $1.27(0.35)$ & $101.9(9.6)$ \\
\hline No $(n=25)$ & $71.3(20.5)$ & $1.07(0.54)$ & $104.8(11.9)$ \\
\hline
\end{tabular}

Values are mean (SD).

${ }^{\star} \mathrm{E} / \mathrm{A}$ ratio: relation between peak velocity of early $(\mathrm{E})$ and late $(\mathrm{A})$ ventricular filling. test. A probability (p) value less than 0.05 was considered significant.

Left ventricular mass index and diastolic function indices, E/A ratio, and isovolumic relaxation time were analysed against systolic and diastolic blood pressure, heart rate, anthropometric measures, CD 4 counts, virus load, CDC stage of the infection, treatment, and time from the diagnosis of infection. The relation of covariates (anthropometric measures, CD4+ T cell count, virus load, CDC stage of infection, treatment, heart rate, and systolic and diastolic blood pressure) with LVMI and E/A ratio or isovolumic relaxation time was initially assessed by univariate analysis. Multivariate analyses were performed by stepwise logistic regression. In these analyses, left ventricular mass index and diastolic function indices, E/A ratio, and isovolumic relaxation time were the dependent variables; variables associated with these in the univariate analysis and other potentially related factors were the independent variables in the models. The analysis included testing for an interaction between the different variables. ${ }^{17}$

\section{Results}

Characteristics of the study population are given in table 1 . All the patients had a normal ECG at rest. Weight, BMI, triceps skinfold thickness, and mid-arm fat and muscle areas were significantly lower in HIV infected patients than in the healthy control group.

LEFT VENTRICULAR MASS INDEX

Left ventricular mass index was significantly depressed in HIV infected patients compared with the healthy controls (table 2).

We examined the influence of nutritional status on the measured cardiac variables. Of the HIV infected patients, $42.6 \%$ (26 of 61) were classified as malnourished as defined above. Malnourished (mean (SD) BMI 19.5 (1.7) $\mathrm{kg} / \mathrm{m}^{2}$ ) and well nourished patients (BMI $24.3(1.8) \mathrm{kg} / \mathrm{m}^{2}$ ) had similar CD4+ $\mathrm{T}$ cell counts (285.3 (420.0) $v 292.4(297.7)$ cells $\times$ $\left.10^{6} / 1, \mathrm{p}>0.05\right)$ and HIV virus load (142 073.9 (180 938.3) v 178859.6 (363 055.8) copies/ $\mathrm{ml}, \mathrm{p}>0.05)$. There was no difference in mean left ventricular end diastolic diameter in well nourished and malnourished patients. LVMI was decreased in the malnourished group $(\mathrm{p}<0.05)$ compared with the HIV infected well nourished patients, while even the well nourished HIV infected patients still had a significantly lower LVMI than the healthy controls $(\mathrm{p}<0.001)$ (table 2).

The influence of antiretroviral treatment, immune status, previous opportunistic diseases, and serum virus load was considered. LVMI was similar in patients on antiretroviral treatment and in those not receiving treatment. There was no significant difference in LVMI when patients with previous opportunistic diseases (CDC stage C) were compared with those without opportunistic diseases, or when individuals with CD4 $+\mathrm{T}$ cell counts lower than or higher than $200 \times 10^{6} / 1$ were compared (table 3). 
Table 4 Multiple linear regression model of variables associated with left ventricular mass index, E/A ratio, and isovolumic relaxation time

\begin{tabular}{|c|c|c|c|c|c|}
\hline Dependent variable & Independent variables & $\beta$ & $95 \%$ Confidence interval & $p$ Value & $\begin{array}{l}\text { Multiple } R \\
\text { (p value) }\end{array}$ \\
\hline Left ventricular mass index & $\begin{array}{l}\text { Mid-arm fat area } \\
\text { Mid-arm muscle area }\end{array}$ & $\begin{array}{l}0.033 \\
1.015\end{array}$ & $\begin{array}{l}0.047 \text { to } 0.018 \\
1.924 \text { to } 0.106\end{array}$ & $\begin{array}{l}<0.001 \\
0.029\end{array}$ & 0.609 \\
\hline $\mathrm{E} / \mathrm{A}$ ratio & $\begin{array}{l}\text { Heart rate } \\
\text { Systolic blood pressure } \\
\text { Diastolic blood pressure }\end{array}$ & $\begin{array}{l}-0.015 \\
0.013 \\
-0.016\end{array}$ & $\begin{array}{l}-0.023 \text { to }-0.008 \\
0.002 \text { to } 0.024 \\
-0.028 \text { to }-0.005\end{array}$ & $\begin{array}{l}<0.001 \\
0.014 \\
0.005\end{array}$ & 0.588 \\
\hline Isovolumic relaxation time & Mid-arm muscle area & -0.311 & -0.024 to -0.597 & 0.036 & 0.036 \\
\hline
\end{tabular}

E/A ratio, relation between peak velocity of early $(\mathrm{E})$ and late $(\mathrm{A})$ ventricular filling.

In 40 patients, serum was taken and stored at the time of the ultrasonographic examination. These patients were classified according to their virus load into two groups: less than 10000 copies $/ \mathrm{ml}(\mathrm{n}=15$; mean (SD) virus load, 2354 (2850) copies $/ \mathrm{ml}$ ), and more than 10000 copies $/ \mathrm{ml}(\mathrm{n}=25 ; 262692$ (353 491) copies $/ \mathrm{ml}$ ). The group with the greater virus load had a significantly lower LVMI (table 3).

The relation between LVMI and nutritional, immunological, viral, or therapeutic variables was analysed by univariate analysis. A significant correlation was detected between LVMI and BMI $(r=0.31, \mathrm{p}=0.02)$ but not with any of the other variables, including virus load. Linear regression showed that only BMI was associated with LVMI. When nutritional indices reflecting BMI (mid-arm fat area, mid-arm muscle area, serum albumin) were included in the model, it was found that LVMI was correlated with both mid-arm fat area and mid-arm muscle area (table 4).

DIASTOLIC VARIABLES

HIV infected patients had a significantly decreased $\mathrm{E} / \mathrm{A}$ ratio compared with the healthy controls. Well nourished and malnourished patients had similar E/A ratios (table 2). A decreased $\mathrm{E} / \mathrm{A}$ ratio was found in patients with less than $200 \times 10^{6} \mathrm{CD} 4+$ cells/litre and in those in CDC stage $\mathrm{C}$ (table 3 ). The $\mathrm{E} / \mathrm{A}$ ratio was related to heart rate $(r=-0.45, \mathrm{p}<0.01)$, serum albumin $(r=0.34, \mathrm{p}<0.01)$, and CD4+ cells/litre $(r=0.27, \mathrm{p}=0.03)$ in the univariate analysis. Linear regression analysis showed that the E/A ratio was significantly related to haemodynamic variables (heart rate, systolic blood pressure, and diastolic blood pressure) (table 4).

Finally, there was a significantly greater isovolumic relaxation time in HIV infected patients than in the controls, while well nourished and malnourished patients showed similar values (table 2). Isovolumic relaxation time was not correlated with immunological, viral, or therapeutic variables (table 3). Univariate and multiple linear regression analyses showed that isovolumic relaxation time was correlated with mid-arm muscle area (table 4).

\section{Discussion}

LEFT VENTRICULAR MASS IN HIV INFECTED

PATIENTS

Our study shows a decrease in left ventricular mass index in HIV infected patients. There have been conflicting results in previous reports on LVMI in these patients. Coudray et al, for example, could not detect any difference between LVMI values in HIV patients and controls. ${ }^{11}$ However, the control population used was not matched for age or sex, and both these variables are known to affect LVMI. ${ }^{18}$ On the other hand, Samaan et $a l^{7}$ analysing patients with AIDS associated wasting, observed a decrease in LVMI, in agreement with our results.

Several predisposing factors have been related to the decrease in left ventricular mass in HIV infected patients. These include a more profound degree of immune depression, ${ }^{2}{ }^{10}$ opportunistic infections, ${ }^{5}$ previous treatment with zidovudine, ${ }^{6}$ and malnutrition. ${ }^{7}$ However, the co-occurrence of several factors in the same patient and the absence of multivariate analysis make interpretation of these results difficult. In this study we showed that LVMI was significantly affected by serum virus load, while patients with a greater virus load also had a decreased BMI (data not shown).

The results of our multivariate analysis showed that the decreased left ventricular mass in patients infected with HIV was correlated with nutritional status, mainly with reserves of fat and somatic protein. Virus load, CD4+ cell counts, past infections, and current treatment were not related to the decrease in ventricular mass.

The relation between myocardial mass and nutritional status in these HIV patients is similar to that found in other forms of undernutrition. ${ }^{19}$ Nevertheless, the reduction in myocardial mass in our patients was not entirely explained by the reduction in BMI-thus left ventricular mass was also significantly depressed in our well nourished HIV infected patients in comparison with the healthy controls. This suggests that other factors may be implicated in the decrease in ventricular mass. Possible candidates are functional abnormalities related to HIV infection of the cardiac myocytes ${ }^{4}$ and immune or fibrotic mechanisms related to the HIV infection. ${ }^{20}$

\section{ABNORMALITIES OF DIASTOLIC FUNCTION IN HIV} INFECTED PATIENTS

We also showed that there were alterations in diastolic function in HIV infected patients. These consisted of a reduced peak of early ventricular filling, an increased peak of late ventricular filling, and an altered isovolumic relaxation time. Modifications of the E/A ratio were correlated with haemodynamic variables (heart rate, blood pressure) and could not be attributed to treatment, immune depression, virus load, or nutritional alterations. 
Alterations in the isovolumic relaxation time were related to somatic protein mass (as determined by the mid-arm muscle area). Our data are consistent with a disturbance of myocardial relaxation, as seen in patients with anorexia nervosa ${ }^{21}$ and in experimentation animals subjected to starvation; in the latter, myofibrillar atrophy, interstitial oedema, and decreased glycogen content have been related to the decrease in ventricular compliance. ${ }^{22}$ Diastolic alterations precede systolic abnormalities in other cardiac pathologies, such as hypertensive myocardiopathy. ${ }^{23}$

CONCLUSIONS

With improved clinical surveillance and treatment, more HIV patients are surviving potentially fatal opportunistic infections only to succumb to neoplasia or terminal organ damage. Heart disease is one such complication, and HIV seems destined to became an important cause of cardiac failure worldwide. ${ }^{2}$ The influence of nutritional factors on the cardiac variables studied here suggests that nutritional measures could help prevent such an outcome.

1 Cohen IS, Anderson DW, Virmani R, et al. Congestive cardiomyopathy in association with the acquired immunodeficiency syndrome. $N$ Engl f Med 1986;315:628-30.

2 Currie PF, Jacob AJ, Foreman AR, et al. Heart muscle disease related to HIV infection: prognostic implications. BMF 1994;309:1605-7.

3 Himelman RB, Chung WS, et al. Cardiac manifestations of human immunodeficiency virus infection: a twodimensional echocardiographic study. $7 \mathrm{Am}$ Coll Cardiol 1989;13:1030-6.

4 Rodriguez ER, Nasim S, Hsia J, et al. Cardiac myocytes and dendritic cells harbor immunodeficiency virus in infected patients with and without cardiac dysfunction: detection by multiplex, nested, polymerase chain reaction in individumultiplex, nested, polymerase chain reaction in individually microdissected cells from right ventricular endom

5 Altieri PI, Climent C, Lazala G, et al. Opportunistic invasion of the heart in hispanic patients with acquired immunodeficiency syndrome. Am f Trop Med Hyg 1994;51:56-9.

6 Lipshultz SE, Orav EJ, Sanders SP, et al. Cardiac structure and function in children with human immunodeficiency virus infection treated with zidovudine. $N$ Engl $7 \mathrm{Med}$ 992;327:1260-5.

7 Samaan SA, Foster A, Raizada V, et al. Myocardial atrophy in acquired immunodeficiency syndrome-associated wasting. Am Heart f 1995;130:823-7.

8 Lewis W. AIDS: cardiac findings from 115 autopsies. Prog Cardiovasc Dis 1993;32:207-15.

9 Cheitlin MD. Cardiac involvement in HIV disease. In: Cohen PT, Sande MA, Volberding PA, eds. The AIDS knowledge base, $4^{\text {th }}$ ed. San Francisco: Little Brown, 1994: section 5.14, 1-14.

10 Jacob AJ, Sutherland GR, Bird AG, et al. Myocardial dysfunction in patients infected with HIV: prevalence and dysfunction in patients infected with HIV:
risk factors. Br Heart $\mathcal{F}$ 1992;68:549-53.

11 Coudray N, de Zuttere D, Force G, et al. Left ventricular diastolic function in asymptomatic and symptomatic human immunodeficiency virus carriers : an echocardiographic study. Eur Heart $\mathcal{F}$ 1995;16:61-7.

12 Centers for Diseases Control: 1993 revised classification system for HIV infection and expanded surveillance case definition for AIDS among adolescents and adults. MMWR 1992;41:RR-17.

13 Parisien C, Gelinas MD, Cossette M. Comparison of anthropometric measures of men with HIV: asymptomatic, symptomatic and AIDS. F Am Diet Assoc 1993;93:1404-8.

14 Ricart W, González F, Conde V y grup per l'evaluacio de la composicio corporal de la población de Catalunya. Valoración del estado nutricional a través de la determinación de los parámetros antropométricos. Nuevas tablas de la población laboral catalana. Med Clin (Barc) de la población

15 Devereux RB, Reicheck N. Echocardiographic determinaion of left ventricular mass in man. Anatomic validation of the method. Circulation 1977;55:613-18.

16 Levy D, Savage DD, Garrison RJ, et al. Echocardiography criteria for left ventricular hypertrophy: the Framingham Heart Study. Am 7 Cardiol 1987;59:956-60.

17 Hosmer DW, Lemeshow S. Applied logistic regression. New York: John Wiley, 1989.

18 Kitzman DW, Scholz DG, Hagen PT, et al. Age-related changes in normal human hearts during the first 10 decades of life. Part II (maturity): a quantitative anatomic decades of life. Part II (maturity): a quantitative anatomic Mayo Clin Proc 1988;63:137-46.

19 Scocken DD, Holloway D, Powers PS. Weight loss and the heart. Effects of anorexia nervosa and starvation. Arch Intern Med 1989;149:877-81.

20 Pantaleo G, Graziosi C, Fauci AS. The immunopathogenesis of human immunodeficiency virus infection. $N$ Engl f Med 1993;328:327-35.

21 Moodie DS. Anorexia and the heart. Postgrad Med 1987;82: $46-61$

22 Abel RM, Grimes JB, Alonso D. Adverse hemodynamic and ultrastructural changes in dog hearts subjected to proteinultrastructural changes in dog hearts subjected to
calorie malnutrition. Am Heart $\mathcal{7}$ 1979;97:733-44.

23 Pearson AC, Labovitz AJ, Mrosek D, et al. Assessment of diastolic function in normal and hypertrophied hearts: comparison of Doppler echocardiography and M-mode echocardiography. Am Heart f 1987;113:1417-25. 